\title{
Regulation by diet and liver of brain metabolism of nutritionally essential polyunsaturated fatty acids*
}

\author{
Stanley I. RAPOPORT \\ Jagadeesh S. RAO \\ Miki IGARASHI
}

Brain Physiology and Metabolism Section, National Institute on Aging,

National Institutes of Health, Building 9,

Room 1S128, 9000 Rockville Pike,

Bethesda, MD 20892 USA

<sir@helix.nih.gov>

\begin{abstract}
It is possible to inject radiolabeled polyunsaturated fatty acids (PUFAs) intravenously to quantify rates of brain and liver PUFA metabolism in the intact organism, in relation to diet, aging or disease. Because circulating $\alpha$-linolenic acid ( $\alpha$-LNA, 18:3n-3) and linoleic acid (LA, 18:2n-6) in plasma do not contribute to brain docosahexaenoic acid (DHA, 22:6n-3) or arachidonic acid (AA, 20:4n-6), respectively, and $D H A$ and $A A$ cannot be synthesized de novo in vertebrate tissue, rates of incorporation of circulating DHA or AA into brain provide exact measurements of their rates of consumption by brain. Using positron emission tomography imaging, we reported that the adult human brain consumes $A A$ and DHA at rates of 17.8 and $4.6 \mathrm{mg} /$ day, respectively, and that the rate of $A A$ consumption doesn't change with age. In unanesthetized adult rats fed an n-3 PUFA "adequate" diet containing $4.6 \%$ (of total fatty acids) $\alpha$-LNA as its only $n-3$ PUFA, the liver secretes DHA derived from circulating $\alpha$-LNA ten-times faster than the brain consumes DHA; thus the liver is capable of supplying all the brain's DHA. With a low dietary $\alpha$-LNA level, rat liver coefficients of $\alpha$-LNA conversion to DHA are increased because of increased liver elongase and desaturase activities, and DHA loss from brain is slowed due to downregulated DHA-metabolizing enzymes, including $\mathrm{Ca}^{2+}$-independent phospholipase $\mathrm{A}_{2}\left(\mathrm{PPLA} \mathrm{A}_{2}\right)$. The $n$-3 PUFA "deficient" diet also increases brain expression of AA-metabolizing enzymes, cytosolic CPLA, secretory sPLA ${ }_{2}$ and cyclooxygenase-2, and the brain docosapentaenoic acid (22:5n-6) concentration. These changes, plus reduced expression of brain derived neurotrophic factor (BDNF) caused by the "deficient" diet, likely increase brain vulnerability to excitotoxicity and inflammation.
\end{abstract}

Key words: docosahexaenoic acid, liver, brain, rat, n-3 PUFAs, imaging, metabolism, phospholipase $A_{2}, B D N F$, diet, arachidonic acid

brain diseases and with cognitive and behavioral defects in development and aging [5-7], and that dietary n-3 PUFA supplementation may be beneficial in some of these conditions $[3,8]$.

Effects on the brain of minor n-3 PUFA dietary deprivation associated with small declines in plasma DHA concentrations of the order found in the clinic have rarely been studied in animal models. Additionally, controversy exists about which dietary PUFA compositions are optimal for human brain function [3, 8-12]. The liver's in vivo capacity to convert $\alpha$-LNA to DHA, or LA to $A A$, has not be quantified in animals or in humans, although changes in this capacity with development, aging or disease likely impact brain PUFA metabolism [13-17].

To address these and related issues, we have developed methods and models to examine PUFA metabolism in the intact organism. The methods include brain imaging with quantitative autoradiography or positron emission tomography (PET), intravenous injection of radiolabeled PUFAs to examine incorporation, turnover and synthesis rates of PUFAs in brain or liver, enzyme assays to evaluate activities of lipid metabolizing enzymes, and molecular techniques to examine transcriptional regulation and protein levels of these enzymes. We have used these approaches to measure AA and DHA brain consumption rates in unanesthetized rats and in human subjects, and to quantify dietary effects in rats on brain and liver PUFA metabolism. We shall discuss the results of these experiments in this paper, when considering three general questions: (1) What are the rates of brain consumption of $\mathrm{AA}$ and $\mathrm{DHA}$ in rats and humans in relation to diet? (2) How does brain DHA depend on dietary n-3 PUFA composition and the liver's ability to convert $\alpha$-LNA to DHA? (3) How do brain lipid enzymes and trophic factors respond to dietary $n-3$ PUFA deprivation?

\section{Methods and models}

$\mathrm{AA}$ and $\mathrm{DHA}$ are found in high concentrations in the stereospecifically numbered (sn)-2 position of brain membrane phospholipids, from where they can be released by selective phospholipase $A_{2}\left(P L A_{2}\right)$ enzymes [18-23]. After release, most of the unesterified AA or DHA will 


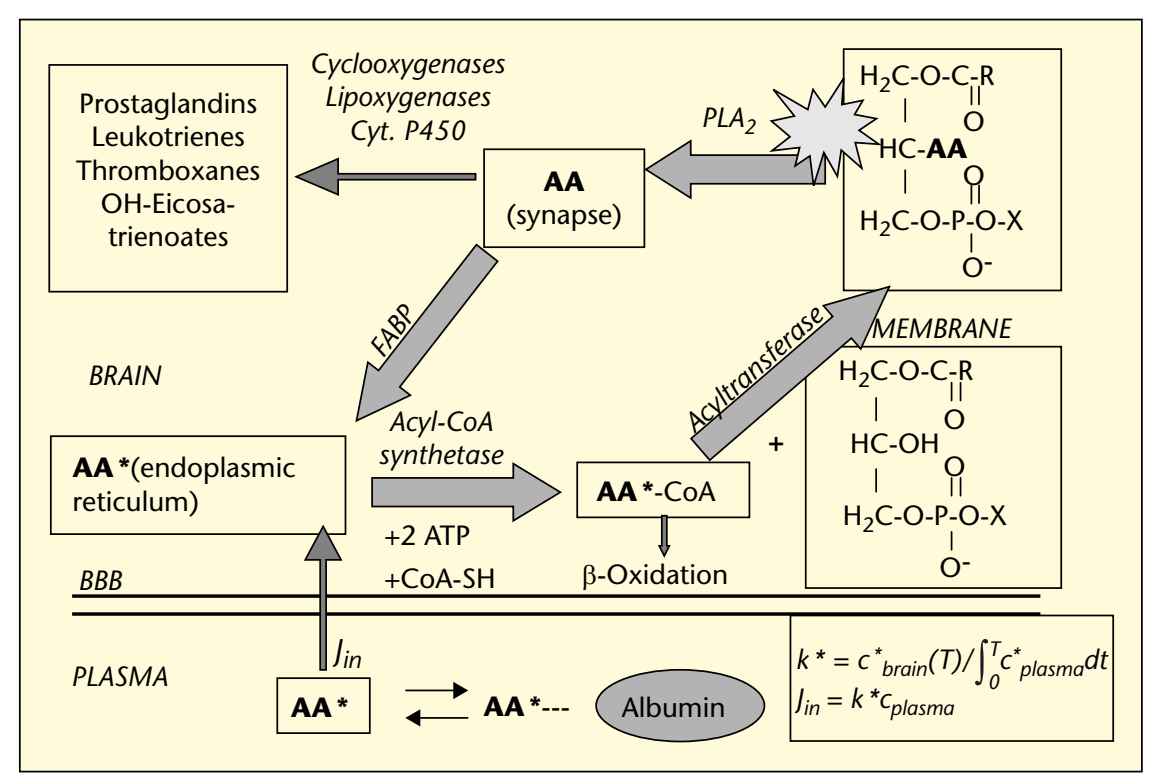

Figure 1. Model of brain arachidonic acid cascade at the synapse. Arachidonic acid (AA), esterified at the sn-2 position of a phospholipid, is liberated by activation (star) of PLA 2 at the synapse. A fraction of the unesterified $A A$ is converted to eicosanoids by cyclooxygenase, lipoxygenase or $P 450$ enzymes, whereas the remainder is transported by a fatty acid binding protein (FABP) to the endoplasmic reticulum. From there, $A A$ is activated to arachidonoyl-COA by an acyl-COA synthetase with the consumption of two ATPs, then esterified into an available lysophospholipid by an acyltransferase. Unesterified AA also can be lost by $\beta$-oxidation in mitochondria or peroxisomes, or by other pathways (not shown). The endoplasmic reticulum compartment is in very rapid equilibrium with unesterified plasma $A A$ that has been released from circulating albumin, whereas the synaptic compartment does not exchange with plasma $A A$. This allows injecting radiolabeled $A A^{*}$ intravenously and determining the incorporation rates $J_{\text {in }}$ of unesterified unlabeled plasma $A A$ into individual membrane phospholipids, as well as $A A$ turnover rates and half-lives in those phospholipids. From [37].

be rapidly reincorporated into an available lysophospholipid via the acyl-CoA pool, through serial actions of an acyl-CoA synthetase and acyltransferase with the consumption of two molecules of ATP (figure 1) [24]. A small fraction, however, will be lost through any of a number of catabolic pathways, including $\beta$-oxidation and conversion to eicosanoids or docosanoids by cyclooxygenases (COXs), lipoxygenases, or cytochrome P450 [25-29]. Neither AA nor DHA is converted significantly $(<1 \%)$ in brain from its respective precursor, LA or $\alpha$-LNA (figure 2) [30, 31], and neither can be synthesized de novo in vertebrate tissue [32]. However, the quantity of AA or DHA that is lost from brain by metabolism will be rapidly and stoichiometrically replaced by the unesterified PUFA in plasma [33]. Replacement occurs independently of changes in cerebral blood flow at a rate $J_{\text {in }}$ (Eq. 2 below) [27, 30, 31, 34-39].

\footnotetext{
Abbreviations: $\mathrm{AA}$, arachidonic acid; $\mathrm{DHA}$, docosahexaenoic acid; LA, linoleic acid; PET, positron emission tomography; PUFA, polyunsaturated fatty acid; $\mathrm{PLA}_{2}$, phospholipase $\mathrm{A}_{2} ; \alpha$-LNA, $\alpha$-linolenic acid; $B D N F$, brain derived nerve growth factor; CREB, CAMP response element-binding protein; EPA, eicosapentaenoic acid; DPA, docosapentaenoic acid; MAP, mitogen activated protein; $s n$, stereospecifically numbered; COX, cyclooxygenase
}

esters of rodent liver and brain, after subjecting the organ to high energy microwaving to stop its metabolism, then measuring PUFA specific activities in organ lipid compartments.

For neuroimaging, an incorporation coefficient $k^{*}(\mathrm{ml} / \mathrm{sec} / \mathrm{g}$ brain) is calculated as regional brain radioactivity divided by the integrated plasma radioactivity of the unesterified $\mathrm{AA}$ or DHA (input function),

$$
k^{*}=\frac{C_{\text {brain }}^{*}(T)}{\int_{0}^{T} C_{\text {plasma }}^{*} d t}
$$

where $\mathrm{t}$ is time after beginning tracer infusion, $c_{\text {brain }}^{*}(T) \mathrm{nCi} / \mathrm{g}$ is brain radioactivity at time $\mathrm{T}$ of sampling (often $5 \mathrm{~min}$ ), and $c_{\text {plasma }}^{*}(T) \mathrm{nCi} / \mathrm{ml}$ is plasma radioactivity. $J_{\text {in }} \mathrm{nmol} / \mathrm{sec} / \mathrm{g}$ brain equals $k^{*}$ multiplied by the unlabeled unesterified plasma AA or DHA concentration, $c_{\text {plasma }} \mathrm{nmol} / \mathrm{ml}$,

$$
J_{\text {in }}=k^{*} C_{\text {plasma }}
$$

The half-life $t_{1 / 2}$ is calculated from the esterified brain concentration $c_{\text {brain }}$ and the incorporation rate,

$$
t_{1 / 2}=0.693 c_{\text {brain }} / J_{\text {in }}
$$

The incorporation rate $J_{\text {in, }}$ determined following the intravenous infusion of a radiolabeled PUFA using Eq. 3, equals the rate of PUFA loss from brain, Jloss (see above),

$$
J_{\text {loss }}=0.693 c_{\text {brain }} / t_{1 / 2}
$$

In unanesthetized rodents and in human subjects, we have quantified $/$ in by infusing intravenously injected albumin-bound radiolabeled AA or DHA, then imaging regional brain radioactivity. We also have quantified / in $_{\text {into individual }}$ phospholipids, triacylglycerols and cholesteryl

This is illustrated, for example, in figure 3 (left) for DHA, where the half-life of DHA loss from rat brain was calculated from the rate of decline of brain $\left[4,5-{ }^{3} \mathrm{H}\right] \mathrm{DHA}$ following its intracerebral injection [36].

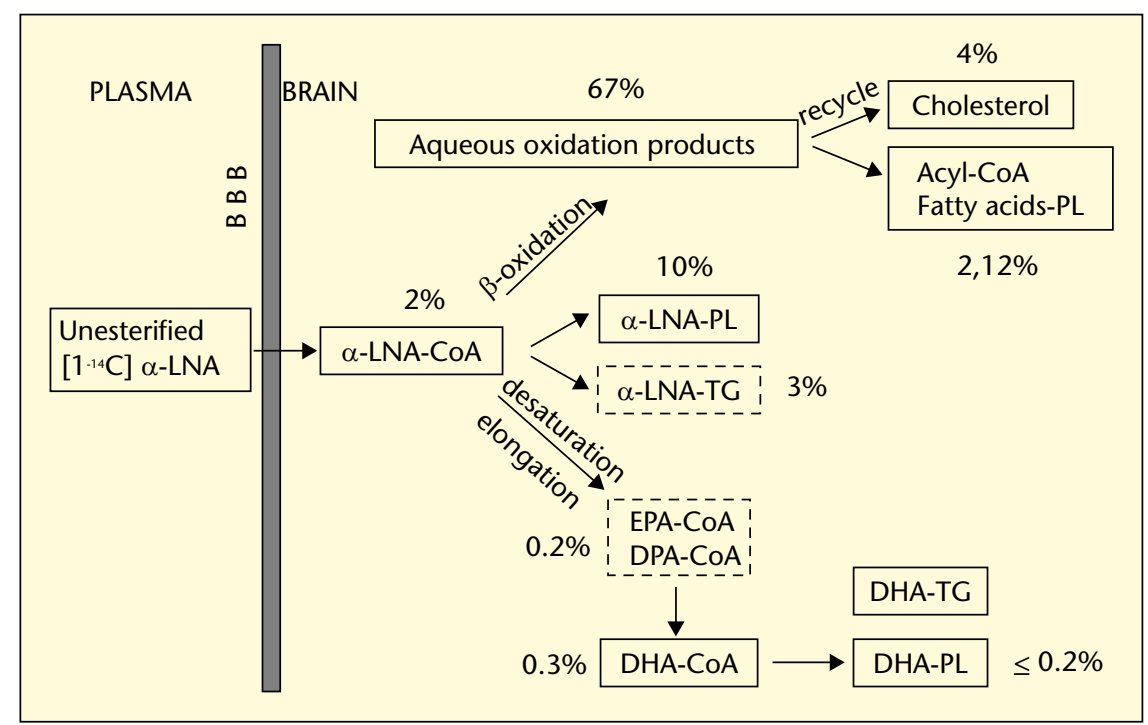

Figure 2. Fractional distribution of $\left[1-{ }^{14} \mathrm{C}\right] \alpha$-LNA in different lipid compartments of rat brain, following 5 min of its intravenous infusion in unanesthetized rats on a high 2.3\% DHA containing diet. Less than $1 \%$ of the tracer has been elongated to EPA or DHA in the acyl-CoA, phospholipid(PL) or triacylglycerol (TG) pools. From [30]. 


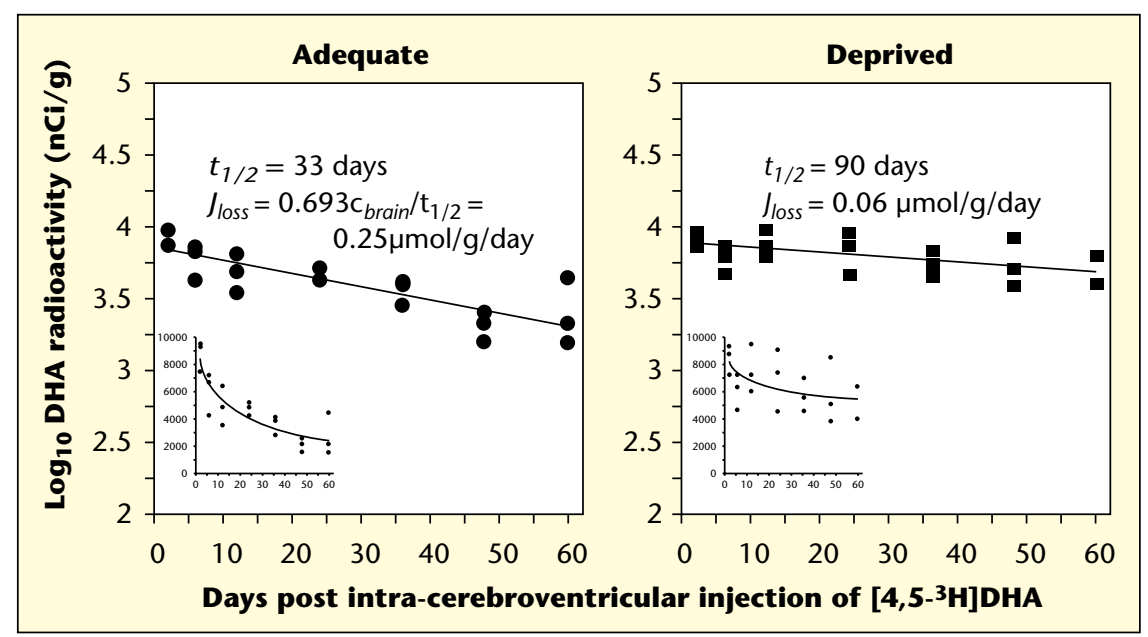

Figure 3. Fifteen weeks of dietary n-3 PUFA deprivation in post-weaning rats prolongs half-life and slows DHA loss in rat brain phospholipid. $\left[4,5-{ }^{3} \mathrm{H}\right] \mathrm{DHA}$ was injected into the brain. Radioactivity due to it was followed in individual phospholipids for 60 days, from which half-lives $t_{1 / 2}$ were calculated (Eq. 3.) I loss was calculated from half-life as illustrated in figure. Adapted from DeMar et al. [36].

Half-lives for net DHA or AA loss from brain (Eqs. 3 or 4), which are of the order of weeks to months in rats $[36,37]$, are much longer than their respective half-lives due to recycling (deacylation-reacylation) (figure 1) [26, 40]. These can be minutes to hours $[37,41]$. Recycling is associated with neurotransmission and rapid, neuroreceptor-initiated $\mathrm{PLA}_{2}$-mediated release of AA or DHA from membrane phospholipid [18, 42], and it is accompanied by high rates of ATP consumption [43].

We have extended our in vivo fatty acid model to quantify coefficients and rates of conversion and esterification of circulating $\alpha$-LNA to DHA into "stable" brain and liver lipids $i[16,17,30$, 31, 44]. The appropriate equations relate $\left[1-{ }^{14} \mathrm{C}\right] \mathrm{DHA}$ radioactivity within "stable" lipids $i$ following intravenous $\left[1-{ }^{14} \mathrm{C}\right] \alpha$-LNA infusion, to the organ's integrated exposure to the tracer in plasma. For the liver, the conversion coefficient is given in units of $\mathrm{mL} / \mathrm{sec} / \mathrm{g}$ liver,

$$
k_{i(\alpha-L N A \rightarrow D H A)}^{*}=\frac{C_{\text {liver }(D H A), i}^{*}(T)}{\int_{0}^{T} C_{\text {plasma }(\alpha-L N A)}^{*} d t}
$$

whereas the conversion rate in units of $\mathrm{nmol} / \mathrm{sec} / \mathrm{g}$ liver equals,

$$
\int_{i n, i(\alpha-L N A \rightarrow D H A)}=k_{i(\alpha-L N A-D H A)}^{*} C_{\text {plasma }(\alpha-L N A)}
$$

where $c_{\text {liver(DHA), }}^{*}(T) \mathrm{nCi} / \mathrm{g}$ is $\mathrm{DHA}$ radioactivity in

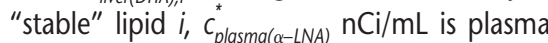
radioactivity due to unesterified $\left[1-{ }^{14} \mathrm{C}\right] \alpha-\mathrm{LNA}$, and $C_{\text {plasma( } \alpha-L N A)} \mathrm{nmol} / \mathrm{mL}$ is the plasma concentration of unesterified unlabeled $\alpha$-LNA. The rate of secretion by liver of the DHA that it has synthesized from total plasma $\alpha$-LNA can be estimated by summing equations 6 for $i=$ phospholipid, triacylglycerol and choles- teryl ester, then dividing by a "dilution" factor $\lambda_{\alpha-L N A-C O A}[17,27,44]$. This factor equals the steady-state ratio of specific activity of liver
a-LNA-CoA to specific activity of plasma unesterified $\alpha$-LNA, during infusion of $\left[1-{ }^{14} \mathrm{C}\right] \alpha$ LNA,

Rate of secretion $=\sum \int_{i n, i(\alpha-L N A \rightarrow D H A)} / \lambda_{\alpha-L N A-C O A}$

\section{Results and questions}

Question 1: What are the rates of brain consumption of $A A$ and $D H A$ in rats and humans in relation to diet?

\section{Studies in unanesthetized rats}

To examine how brain PUFA metabolism is related to dietary PUFA composition, we quantified brain consumption rates of DHA in relation to the liver's ability to convert circulating $\alpha$-LNA to DHA in rats that had been fed, for 15 weeks post-weaning (starting at 21 days of age), one of three diets (table 1, row 1): (1) a high DHA-containing diet (DHA $2.3 \%$ of total fatty acids, 5.1\% $\alpha$-LNA, 4\% fat); (2) a DHAfree diet containing $4.6 \% \alpha$-LNA (of total fatty acids), $10 \%$ fat; or (3) a DHA-free diet containing $0.2 \% \alpha$-LNA, $10 \%$ fat. We term the latter two diets n-3 PUFA "adequate" and "deficient", respectively, following the convention
Table 1. Plasma and brain parameters in unanesthetized rats fed different diets for 15 weeks. Row 1: dietary composition; row 2: unesterified plasma concentrations of $\alpha$-LNA and DHA (in brackets); row 3: unesterified plasma concentrations of AA and DPAn-6 (in brackets); row 5: AA and DPAn-6 (in brackets) concentrations in brain phospholipids; row 6: incorporation coefficient calculated by Eq. 1; row 7, incorporation rate calculated by Eq. 2; row

\begin{tabular}{|c|c|c|c|c|c|}
\hline \multirow[b]{2}{*}{1} & \multirow[b]{2}{*}{ Parameter } & \multirow[b]{2}{*}{ Units } & \multicolumn{3}{|c|}{ Diet during 15 weeks post-weaning } \\
\hline & & & $\begin{array}{c}\text { High DHA diet } \\
\text { (5.1\% } \alpha \text {-LNA, } \\
2.3 \% \text { DHA, } \\
4 \% \text { fat) }\end{array}$ & $\begin{array}{c}\text { High } \alpha \text {-LNA } \\
\text { diet (4.6\% } \alpha \text { - } \\
\text { LNA, } \\
\text { no DHA, } \\
10 \% \text { fat) }\end{array}$ & $\begin{array}{c}\text { n-3 PUFA } \\
\text { inadequate } \\
\text { diet }(0.2 \% \\
\alpha \text {-LNA, no } \\
\text { DHA, } 10 \% \text { fat })\end{array}$ \\
\hline 2 & $\begin{array}{l}c_{\text {plasma }}(\alpha-\text { LNA }) \\
{\left[c_{\text {plasma }}(D H A)\right]}\end{array}$ & $\mathrm{nmol} / \mathrm{ml}$ & $\begin{array}{l}41 \pm 13^{\# a} \\
{[26 \pm 12]^{a}}\end{array}$ & $\begin{array}{c}27 \pm 6^{\#} \\
{[6.5 \pm 2.6]^{b}}\end{array}$ & $\begin{array}{c}1.0 \pm 0.45^{*} \\
{[0.23 \pm 0.10]^{* b}}\end{array}$ \\
\hline 3 & $\begin{array}{l}\text { clasma }_{\text {plaA }}(\text { A } \\
{\left[C_{\text {plasma }}(D P A n-6]\right.}\end{array}$ & $\mathrm{nmol} / \mathrm{ml}$ & $\begin{array}{l}22.5 \pm 5.6 \\
{[2.3 \pm 1.2]^{\mathrm{c}}}\end{array}$ & $\begin{array}{l}25 \pm 4.8 \\
{[N D]^{b}}\end{array}$ & $\begin{array}{c}34 \pm 5.9 \\
{[8.7 \pm 1.1]^{\star b}}\end{array}$ \\
\hline 4 & $\begin{array}{l}\text { DHA concentration } \\
\text { in brain } \\
\text { phospholipid, c brain }\end{array}$ & $\mu \mathrm{mol} / \mathrm{g}$ & $\begin{array}{l}17.6 \pm 2.8^{\mathrm{a}} \\
13.8 \pm 4.9^{\mathrm{c}}\end{array}$ & $12.0 \pm 2.4^{d}$ & $7.6 \pm 1.5^{\star d}$ \\
\hline 5 & $\begin{array}{l}\text { Concentrations of } \\
\text { AA and [DPAn-6] in } \\
\text { brain phospholipid }\end{array}$ & $\mu \mathrm{mol} / \mathrm{g}$ & $\begin{array}{c}11.1 \pm 2.9^{c} \\
{[0.1 \pm 0.04]^{c}}\end{array}$ & $\begin{array}{c}9.4 \pm 1.1^{d} \\
{[0.25 \pm 0.06]^{d}}\end{array}$ & $\begin{array}{c}9.8 \pm 1.5^{\mathrm{d}} \\
{[4.4 \pm 1.8]^{* \mathrm{~d}}}\end{array}$ \\
\hline 6 & $\begin{array}{l}\text { DHA incorporation } \\
\text { coefficients, } k^{*}\end{array}$ & $\mathrm{ml} / \mathrm{s} / \mathrm{g} \times 10^{-4}$ & $2.2 \pm 0.2^{f}$ & $1.99 \pm 0.3^{\mathrm{e}}$ & $2.83 \pm 0.6^{\star \mathrm{e}}$ \\
\hline 7 & $\begin{array}{l}\text { Rate DHA } \\
\text { incorporation, } J_{\text {in }}^{\#}\end{array}$ & $\mathrm{nmol} / \mathrm{s} / \mathrm{g} \times 10^{-4}$ & $17.4 \pm 2.0^{f}$ & $22.0 \pm 5.0^{\mathrm{e}}$ & $0.23 \pm 0.05^{\star \mathrm{e}}$ \\
\hline 8 & $\begin{array}{l}\text { Daily rate DHA } \\
\text { consumption by } \\
\text { whole }(1.5 \mathrm{~g}) \text { brain }\end{array}$ & $\mu \mathrm{mol} /$ day & $0.23^{f}$ & $0.29^{e}$ & $0.003^{\mathrm{e}}$ \\
\hline
\end{tabular}
8: whole brain DHA incorporation (consumption) rate for $1.5 \mathrm{~g}$ rat brain.

\# Mean \pm SD; AA, arachidonic acid, DHA, docosahexaenoic acid, $\alpha$-LNA, $\alpha$-linolenic acid, DPA, docosapentaenoic acid, ND, not detected; *Differs significantly from mean in high $\alpha$-LNA ( $n-3$ PUFA adequate) diet rats; ${ }^{\#}$ net rate for brain phospholipids. ${ }^{a}[30] ;{ }^{b}[17] ;{ }^{c}[31] ;{ }^{d}[36] ;{ }^{e}[68] ;{ }^{f}[69]$. 
of Bourre [4]. The rats fed the "deficient" compared with "adequate" diet had increased scores on behavioral measures of depression and aggression [45].

The unesterified plasma $\alpha$-LNA concentration in rats fed the n-3 PUFA "adequate" diet was $36 \%$ less than in rats fed the DHA-containing diet, but 27 times higher than in rats fed the "deficient" diet (table 1, row 2). Unesterified plasma AA did not differ markedly among rats on the three diets, whereas the plasma concentration of the AA elongation product, docosapentaenoic acid (DPAn-6, 22:5n-6), while low in rats fed the high DHA or n-3 PUFA "adequate" diet, equaled $8.7 \mathrm{nmol} / \mathrm{mL}$ in rats fed the "deficient" diet (row 3, table 1).

The DHA concentration in brain phospholipid (table 1, row 4) was lower in rats fed the "adequate" than high DHA diet, but was reduced by an additional $4.4 \mu \mathrm{mol} / \mathrm{g}$ in rats fed the "deficient" diet. While AA concentrations in brain phospholipid were about the same in rats on each of the three diets (table 1, row 5), brain DPAn-6 was elevated by $4.2 \mu \mathrm{mol} / \mathrm{g}$ in rats fed the "deficient" diet, compensating for the reduced DHA concentration.

DHA incorporation coefficients $k^{*}$ (Eq. 1) did not vary markedly among the three dietary groups (table 1, row 6), whereas the net rate of DHA incorporation into brain, $J_{\text {in, }}$ thus its rate of loss from brain, was reduced in rats fed the deficient diet (table 1, rows 7 and 8), due to the low plasma DHA concentration with this diet (Eq. 2). Reduced values of $J_{\text {in }}$ for DHA in rats fed the "deficient" diet corresponded to a 3-fold prolongation of the DHA half-life in brain phospholipid (figure 3, right) [36]. Values of $J_{\text {in }}$ for AA can be found elsewhere in unanesthetized mice and rats $[34,35,46,47]$.

\section{PUFA consumption by the human brain}

We also have determined $J_{\text {in }}$ for $\mathrm{AA}$ and DHA in the human brain using PET and the positron emitting tracers, $\left[1-{ }^{11} \mathrm{C}\right] \mathrm{AA}$ and $\left[1-{ }^{11} \mathrm{C}\right] \mathrm{DHA}$, respectively [48-51] (Umhau et al., unpublished results). Whole-brain $J_{\text {in }}$ in healthy adults equaled $17.8 \mathrm{mg} /$ day per $1500 \mathrm{~g}$ brain for $\mathrm{AA}$ (figure 4) [49] and $4.6 \mathrm{mg} /$ day per $1500 \mathrm{~g}$ brain for DHA (Umhau et al., unpublished results). Furthermore, $J_{\text {in }}$ for AA did not decline with healthy aging [49].

Dietary intakes of $n-3$ PUFAs for maintaining optimal human brain PUFA metabolism are not agreed on, but they now might be estimated by relating dietary PUFA composition to PETdetermined brain DHA incorporation (consumption) rates. Different committees have recommended eicosapentaenoic acid (EPA, $20: 5 n-3)+D H A$ intakes of $0.11-0.16 \mathrm{~g} /$ day [52], $0.2 \mathrm{~g} /$ day [10], $0.65 \mathrm{~g} /$ day [11], and $1.6 \mathrm{~g} /$ day [12]. Another committee recom-

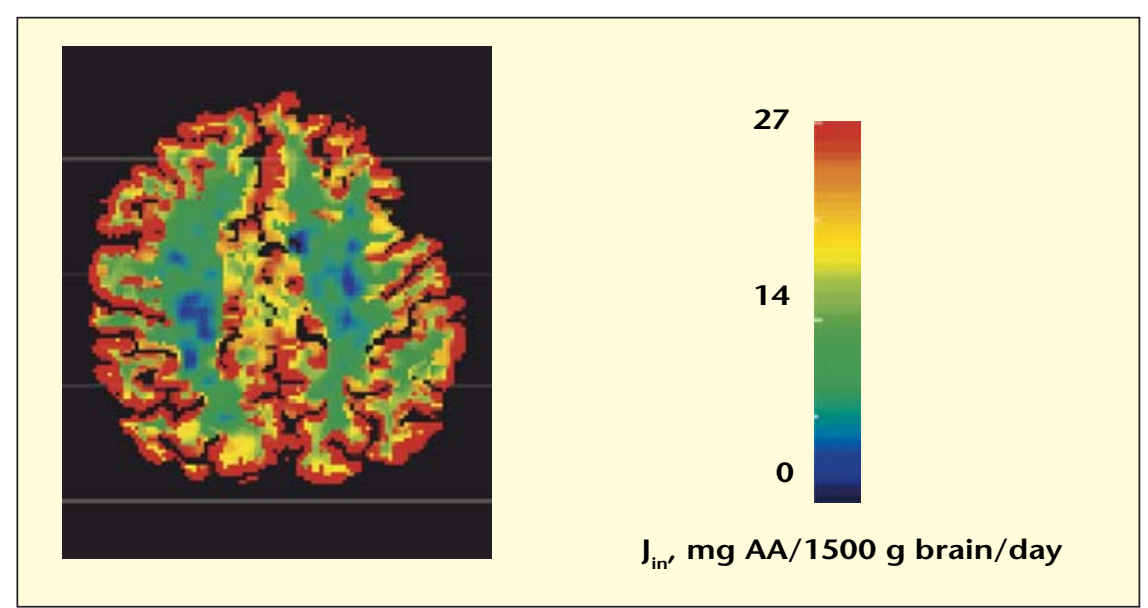

Figure 4. Horizontal section showing regional incorporation rates of plasma unesterified arachidonic acid into human brain, after correction for partial voluming. Rates are given in terms of color-coding. The global rate, obtained by integrating regional rates for whole brain, equaled $17.8 \mathrm{mg} / 1500 \mathrm{~g}$ brain/day. From [49].

mended that adult men and women should consume $1.6 \mathrm{~g} /$ day and $1.1 \mathrm{~g} /$ day, respectively, of $\alpha$-LNA, plus an additional 10\% (0.16$0.11 \mathrm{~g}$ ) representing EPA + DHA [52]. Our PETdetermined $J_{\text {in }}$ for DHA, $4.6 \mathrm{mg} /$ day (see above), equals $2.5-5 \%$ of the estimated average daily dietary intake of EPA + DHA in the United States, $100-200 \mathrm{mg} /$ day [9].

\section{Question 2: How does brain DHA depend on dietary n-3 PUFA composition and the liver's ability to convert $\alpha$-LNA to DHA?}

A large fraction of the world's population does not eat meat or fish for various reasons, but the effects, if any, of low dietary levels of DHA and

Table 2. Calculated liver parameters in unanesthetized rats fed each of three diets, correspond to plasma and brain data of table 1a. Row 2: conversion coefficients calculated by Eq. 5; rows 3 and 4: secretion rates per $g$ and per total liver, calculated by Eq. 6.

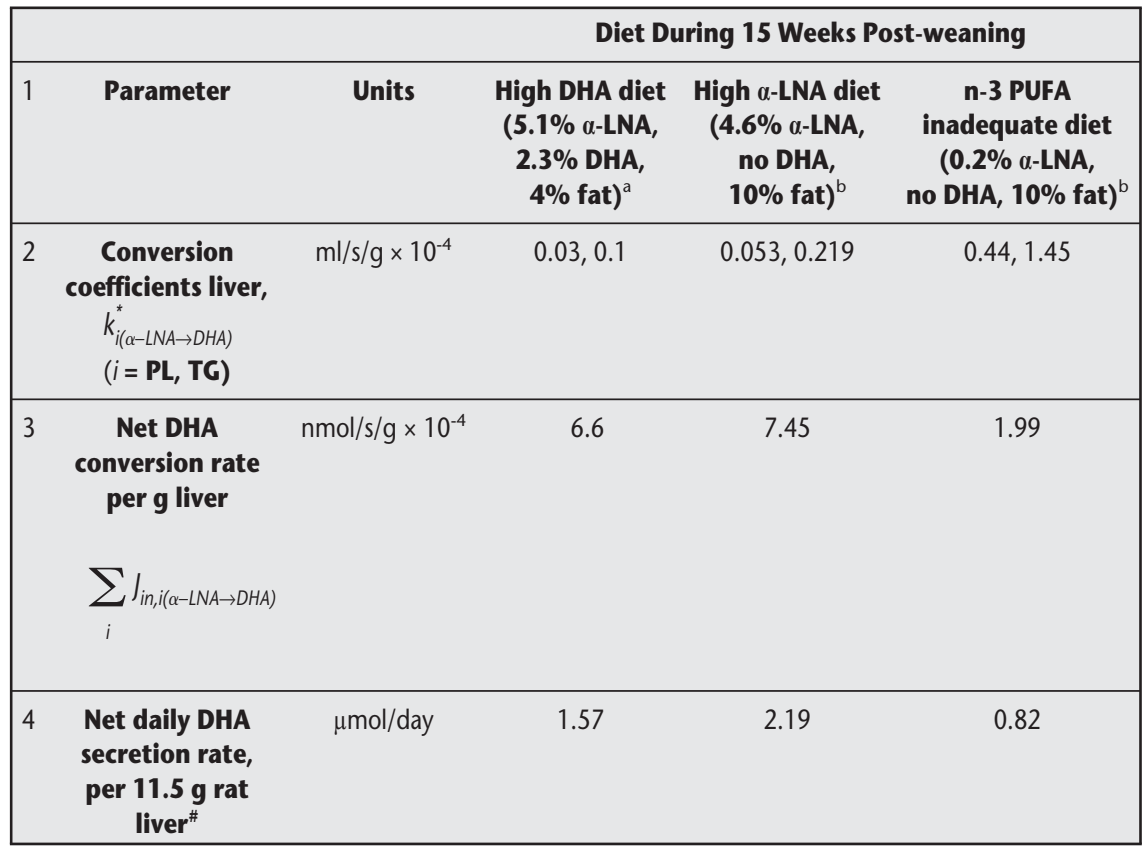

PL, phospholipid; TG, triacylglycerol; \#Calculated by Eq. 7 with $\lambda_{\alpha \text {-LNA-CoA }}$ equal to $0.47,0.34$ and 0.24 for high DHA, 4.6\% $\alpha$-LNA, $0.2 \% \alpha$-LNA diet, respectively. ${ }^{\text {[ }}[44] ;{ }^{\text {b }}[17]$. 
EPA on their brain function have not been identified [53]. In such subjects, the brain's DHA content must depend on the liver's ability to synthesize and secrete DHA from circulating $\alpha$-LNA.

To address the issue of liver synthesis, we estimated the liver's ability to synthesize DHA from $\alpha$-LNA in unanesthetized rats fed each of the three diets discussed above. Row 2 of table 2 gives the calculated conversion coefficients $k_{i(\alpha-L N A \rightarrow D H A)}^{*}($ Eq. 5) of unesterified $\alpha$-LNA to DHA into "stable" liver lipids $i=$ phospholipid (PL) and triacylglycerol (TG), whereas row 3 gives the sum of rates $\int_{\text {in } i(\alpha-I N A \rightarrow D H A)}$ of DHA synthesis followed by incorporation (Eq. 6) into these lipids. Assuming that the liver secretes its newly formed esterified DHA within circulating lipoproteins [54], row 4 presents liver DHA secretion rates, calculated by Eq. 7, in units of $\mu \mathrm{mol} /$ day per $11.5 \mathrm{~g}$ rat liver.

Conversion coefficients of unesterified plasma $\alpha$-LNA into liver phospholipid and triacylglycerol DHA were 2-fold greater in rats fed the $\mathrm{n}-3$ PUFA "adequate" than high DHA diet, and were further increased 7-fold in rats fed the "deficient" diet. The increases corresponded to increased liver activities of the $\Delta 5$ and $\Delta 6$ desaturases and elongases 2 and 5 that mediate conversion of $\alpha$-LNA to DHA and of LA to AA [55] (Igarashi et al., unpublished results). Net liver DHA synthesis and secretion rates were much less in rats on the n-3 PUFA "deficient" than "adequate" diet (table 2, rows 3 and 4), reflecting the low plasma $\alpha$-LNA concentration with the "deficient" diet (Eq. 6). The liver's net DHA synthesis rate in rats fed the DHA-free n-3 PUFA "adequate" diet was about 10-fold the brain's DHA consumption rate (table 1, row 8 ). Thus, liver secretion was sufficient to supply the brain's DHA.

In summary, in rats fed an n-3 PUFA "adequate" diet containing 4.6\% $\alpha$-LNA, brain DHA is maintained entirely by the DHA formed and secreted from circulating $\alpha$-LNA by the liver. When dietary $\alpha$-LNA is reduced, the liver increases its coefficients for DHA synthesis by upregulating activities of relevant desaturases and elongases.

\section{Question 3: How do brain lipid enzymes} and trophic factors respond to dietary $n-3$ PUFA deprivation?

\section{Enzymes of the brain AA and DHA cascades} DHA-loss half life in rat brain (Eq. 4) was prolonged 3-fold in rats fed the n-3 PUFA "deficient" compared with the "adequate" diet (figure 3, right) [36]. This prolongation resulted from the brain's ability to downregulate expression of some of its DHA-metabolizing enzymes. Thus, in rats fed the "deficient" compared with "adequate" diet, brain mRNA, pro-

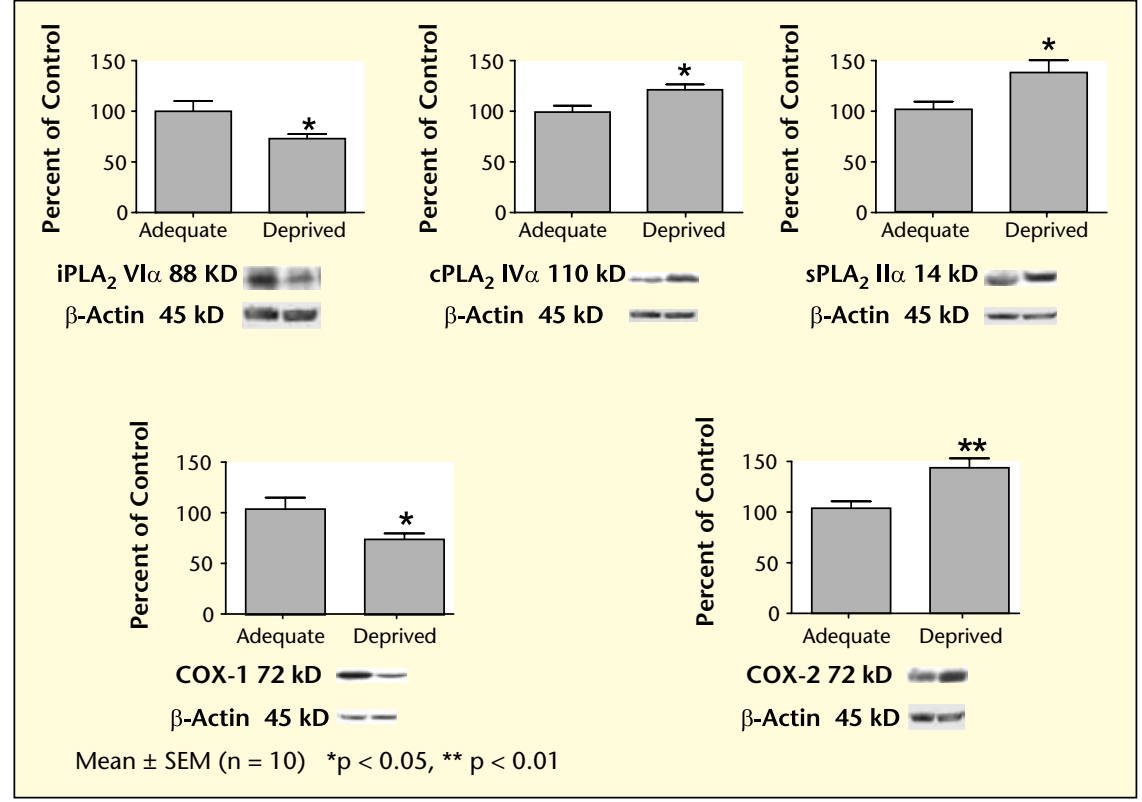

Figure 5. Fifteen weeks of n-3 PUFA dietary deprivation, compared with an n-3 PUFA "adequate" diet, decreases rat frontal cortex $\mathrm{IPLA}_{2}$ and COX-1 protein but increases $S P L A_{2}, C P L A_{2}$ and COX-2 protein. From [56].

tein and activity levels of DHA-selective $\mathrm{Ca}^{2+}$ independent phospholipase $A_{2}\left(\mathrm{iPLA}_{2}\right)$ [22] and of COX-1 were downregulated [56], as illustrated in figure 5. The two affected enzymes are known to be functionally coupled in different tissues [57].

Also illustrated in figure 5, the 15-week n-3 PUFA deficiency upregulated brain $\mathrm{mRNA}$, protein and activity levels of AA-selective CPLA secretory sPLA ${ }_{2}$ and COX-2 [56], enzymes that often are functionally coupled $[23,57,58]$. These changes, in the context of an increased brain DPAn-6 concentration (table 1, row 3), imply that the "deficient" diet upregulated brain n-6 PUFA metabolism.

Excess AA metabolism can contribute to neuronal damage in experimental ischemia, glutamate excitotoxicity, neuroinflammation, and cerebral trauma [42, 59-63]. This implies that n-3 PUFA dietary deficiency would increase brain vulnerability to these insults by increasing brain n-6 PUFA metabolism, whereas dietary n-3 PUFA supplementation would be neuroprotective. In this regard, a low dietary n-3 PUFA content has been suggested to increase brain vulnerability in a number of human diseases, including Alzheimer disease and bipolar disorder, in which neuroinflammation and excitotoxicity play a role, and n-3 PUFA supplementation may be helpful in some of these diseases $[5,6,64,65]$.

\section{BDNF and CREB}

Another way in which dietary n-3 PUFAs may be neuroprotective is by upregulating brain trophic factors. For example, brain derived neurotrophic factor (BDNF) promotes neuronal survival, plasticity, differentiation and growth [66]. Transcription of the BDNF gene is regulated by the CAMP response elementbinding protein (CREB), following CREB's phosphorylation by protein kinases including p38 mitogen activated protein (MAP) kinase [67]. In rats fed the n-3 PUFA "deficient" compared with "adequate" diet, figure 6 shows that brain mRNA and protein levels of BDNF, CREB DNA binding activity, the phosphorylated CREB protein level and p38 MAP kinase activity were reduced significantly [67].

In summary, rats subjected to our 15-week dietary n-3 PUFA deprivation have a reduced brain DHA concentration and a prolonged DHA half-life, accompanied by reduced activities of presumably DHA-selective $\mathrm{IPLA}_{2}$ and COX-1; an increased brain DPAn-6 concentration accompanied by increased activities of AA-selective CPLA, SPLA $_{2}$ and COX-2; and reduced expression of $B D N F$ that corresponds to reduced CREB DNA binding activity and p38 MAP-kinase activity.

\section{Conclusions}

In response to each of the three questions presented in the Introduction, we have shown that: (1) Regional and global brain AA and DHA consumption rates can be and have been quantified in unanesthetized rats, and in humans using PET. (2) In the absence of dietary $\mathrm{DHA}$, a normal brain DHA content can be maintained by liver conversion of $\alpha$-LNA to circulating DHA, provided sufficient $\alpha$-LNA is in 


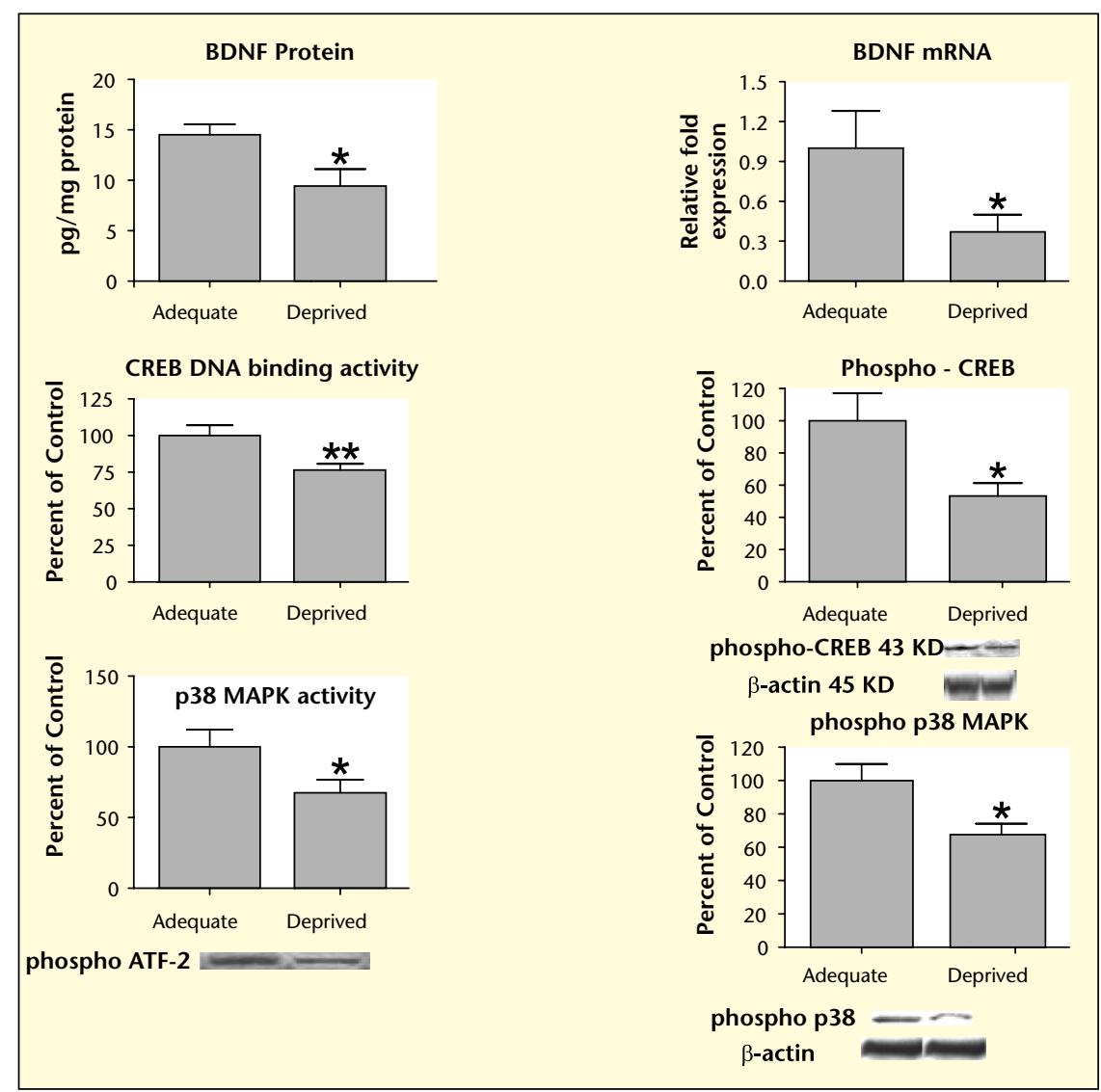

Figure 6. Fifteen weeks of $n$-3 PUFA dietary deprivation, compared with an n-3 PUFA adequate diet, downregulates rat frontal cortex p38 MAP kinase activity and phospho p38 MAP kinase protein, CREB DNA binding activity and phospho-CREB protein, and BDNF protein and mRNA. From [67].

the diet. Liver but not brain conversion coefficients are increased by further $\alpha$-LNA deprivation, in relation to increased expression of liver elongases and desaturases. (3) Brain DHA reduction caused by 15 weeks of dietary $n-3$ PUFA deprivation in rats is associated with slowed DHA loss from brain and reduced expression of presumably DHA-metabolizing enzymes, tending to conserve brain DHA, by increased expression of AA-metabolizing enzymes and a high DPAn-6 concentration, and by reduced $B D N F$, phospho-CREB and p38 MAP kinase activity levels. Some of these changes are consistent with neuroprotective effects of $n-3$ PUFAs.

Now that appropriate quantitative techniques are available for studying the relations among brain and liver PUFA metabolism and diet in animals and humans, future studies using these techniques might address a number of additional relevant questions: (1) To what extent does the liver convert EPA to DHA under different dietary conditions? (2) What are the effects of graded n-3 PUFA dietary deprivation on the markers and kinetics of brain metabolism and function that we have presented in this paper? (3) What are the effects on these markers of dietary n-6 PUFA deprivation? (4) How do liver conversion rates of $\alpha$-LNA and EPA to secreted DHA vary with age and liver disease? (5) In humans, how do brain AA and DHA consumption rates change with aging or disease, and how might human diets be tailored to maintain normal consumption rates with these variable conditions?

Acknowledgements. This work was supported by the Intramural Program of the National Institute on Aging, National Institutes of Health, Bazinet, Dr. David Purdon and Dr. Malden Nesheim for their helpful comments.

\section{REFERENCES}

1. CONTRERAS MA, RAPOPORT SI. Recent studies on interactions between n-3 and n-6 polyunsaturated fatty acids in brain and other tissues. Curr Opin Lipidol 2002; 13: 267-72. fatty acids and the brain: possible health implications. Int I Dev Neurosci 2000; 18: 383-99. Bethesda, Maryland, USA. We thank Dr. Richard

2. YOUDIM KA, MARTIN A, JOSEPH JA. Essential
3. INNIS SM. The role of dietary $n-6$ and n-3 fatty acids in the developing brain. Dev Neurosci 2000; 22: 474-80.

4. BOURRE JM, FRANCOIS M, YOUYOU A, et al. The effects of dietary alpha-linolenic acid on the composition of nerve membranes, enzymatic activity, amplitude of electrophysiological parameters, resistance to poisons and performance of learning tasks in rats. J Nutr 1989; 119: 1880-92.

5. CONQUER JA, TIERNEY MC, ZECEVIC I BETTCER W], FISHER RH. Fatty acid analysis of blood plasma of patients with Alzheimer's disease, other types of dementia, and cognitive impairment. Lipids 2000; 35: 1305-12.

6. NOAGHIUL $S$, HIBBELN JR. Cross-national comparisons of seafood consumption and rates of bipolar disorders. Am / Psychiatry 2003; 160: 2222-7.

7. PAWLOSKY RJ, SALEM JR. N. Alcohol consumption in rhesus monkeys depletes tissues of polyunsaturated fatty acids and alters essential fatty acid metabolism. Alcohol Clin Exp Res 1999; 23: 311-7.

8. STOLL AL, SEVERUS WE, FREEMAN MP, RUETER S, ZBOYAN HA, DIAMOND E. CRESS KK, Marangell LB. Omega 3 fatty acids in bipolar disorder: A preliminary double-blind, placebo-controlled trial. Arch Gen Psychiatry 1999; 56: 407-12.

9. KRIS-ETHERTON PM, TAYLOR DS, YU-POTH S, et al. Polyunsaturated fatty acids in the food chain in the United States. Am / Clin Nutr 2000; 71: 179S-188S.

10. BRITISH NUTRITION FOUNDATION (Ed.). Unsaturated fatty acids nutritional and physiological significance: the report of the British Nutrition Foundation's task force. New York: Chapman and Hall, 1992.

11. SIMOPOULOS AP. Commentary on the workshop statement. Essentiality of and recommended dietary intakes for Omega- 6 and Omega-3 fatty acids. Prostaglandins Leukot Essent Fatty Acids 2000; 63: 123-4.

12. SCIENTIFIC REVIEW COMMITTEE, NUTRITIONAL RECOMMENDATIONS. Report. In, Minister of National Health and Welfare, Canadian Government Publishing Centre, Ottawa, Canada, 1990, p. 208.

13. BOURRE JM, PICIOTTI M. Delta-6 desaturation of alpha-linolenic acid in brain and liver during development and aging in the mouse. Neurosci Lett 1992; 141: 65-8.

14. BURKE PA, LING PR, FORSE RA, LEWIS DW, JENKINS R, BISTRIAN BR. Sites of conditional essential fatty acid deficiency in end stage liver disease. JPEN / Parenter Enteral Nutr 2001; 25: 188-93.

15. SCOTT BL, BAZAN NG. Membrane docosahexaenoate is supplied to the developing brain and retina by the liver. Proc Natl Acad Sci USA 1989; 86: 2903-7. 
16. IGARASHI M, DEMAR Ir. IC, MA K, CHANG L, BELL JM, RAPOPORT SI. Docosahexaenoic acid synthesis from alpha -linolenic acid by rat brain is not altered by dietary N-3 polyunsaturated fatty acid deprivation. I Lipid Res 2007; 48: 1150-8.

17. IGARASHI M, DEMAR Jr. JC, MA K, CHANG L, BELL JM, RAPOPORT SI. Upregulated liver conversion of alpha-linolenic acid to docosahexaenoic acid in rats on a 15 week n-3 PUFAdeficient diet. / Lipid Res 2007; 48: 152-64.

18. DEGEORGE IJ, NARIAI T, YAMAZAKI S, WILLIAMS WM, RAPOPORT SI. Arecolinestimulated brain incorporation of intravenously administered fatty acids in unanesthetized rats. J Neurochem 1991; 56: 352-5.

19. JONES CR, ARAI T, BELL JM, RAPOPORT SI. Preferential in vivo incorporation of [3H]arachidonic acid from blood in rat brain synaptosomal fractions before and after cholinergic stimulation. J Neurochem 1996; 67: 822-9.

20. BAYON Y, HERNANDEZ M, ALONSO A, et al. Cytosolic phospholipase $A_{2}$ is coupled to muscarinic receptors in the human astrocytoma cell line 1321N1: characterization of the transducing mechanism. Biochem / 1997; 323: 281-7.

21. CLARK JD, LIN LL, KRIZ RW, et al. A novel arachidonic acid-selective cytosolic PLA2 contains a $\mathrm{Ca}(2+)$-dependent translocation domain with homology to PKC and GAP. Cell 1991; 65: 1043-51.

22. STROKIN M, SERGEEVA M, REISER G. Prostaglandin synthesis in rat brain astrocytes is under the control of the n-3 docosahexaenoic acid, released by group VIB calcium-independent phospholipase A(2). J Neurochem 2007.

23. DENNIS EA. Diversity of group types, regulation, and function of phospholipase A2. / Biol Chem 1994; 269: 13057-60.

24. PURDON AD, RAPOPORT SI. Energy consumption by phospholipid metabolism in mammalian brain. In: Gibson G, Dienel G, eds. Neural Energy Utilization: Handbook of Neurochemistry and Molecular Biology. New York: Springer, 2007: 401-27.

25. HORROCKS LA, FAROOQUI AA. Docosahexaenoic acid in the diet: its importance in maintenance and restoration of neural membrane function. Prostaglandins Leukot Essent Fatty Acids 2004; 70: 361-72.

26. SUNGY, MACQUARRIE RA. Deacylationreacylation of arachidonoyl groups in cerebral phospholipids. Ann N Y Acad Sci 1989; 559: 37-55.

27. ROBINSON P|, NORONHA |, DEGEORGE II, FREED LM, NARIAI T, RAPOPORT SI. A quantitative method for measuring regional in vivo fatty-acid incorporation into and turnover within brain phospholipids: Review and critical analysis. Brain Res Brain Res Rev 1992; 17: 187 214.
28. FITZPATRICK FA, SOBERMAN R. Regulated formation of eicosanoids. / Clin Invest 2001; 107: 1347-51.

29. SUGIURA T, KONDO S, SUKAGAWA A, et al. Transacylase-mediated and phosphodiesterasemediated synthesis of $\mathrm{N}$-arachidonoylethanolamine, an endogenous cannabinoid-receptor ligand, in rat brain microsomes. Comparison with synthesis from free arachidonic acid and ethanolamine. Eur / Biochem 1996; 240: 53-62.

30. DEMAR Jr. JC, MA K, CHANG L, BELL JM, RAPOPORT SI. alpha-Linolenic acid does not contribute appreciably to docosahexaenoic acid within brain phospholipids of adult rats fed a diet enriched in docosahexaenoic acid. / Neurochem 2005; 94: 1063-76.

31. DEMAR Jr. JC, LEE HJ, MA K, et al. Brain elongation of linoleic acid is a negligible source of the arachidonate in brain phospholipids of adult rats. Biochim Biophys Acta 2006; 1761: 1050-9.

32. HOLMAN RT. Control of polyunsaturated acids in tissue lipids. J Am Coll Nutr 1986; 5: 183-211.

33. WASHIZAKI K, SMITH QR, RAPOPORT SI, PURDON AD. Brain arachidonic acid incorporation and precursor pool specific activity during intravenous infusion of unesterified [3H]arachidonate in the anesthetized rat. / Neurochem 1994; 63: 727-36.

34. BASSELIN M, VILLACRESES NE, LANGENBACH R, MA K, BELL JM, RAPOPORT SI. Resting and arecoline-stimulated brain metabolism and signaling involving arachidonic acid are altered in the cyclooxygenase-2 knockout mouse. / Neurochem 2006; 96: 669-79.

35. BASSELIN M, VILLACRESES NE, LEE HJ, BELL JM, RAPOPORT SI. Flurbiprofen, a cyclooxygenase inhibitor, reduces the brain arachidonic acid signal in response to the cholinergic muscarinic agonist, arecoline, in awake rats. Neurochem. Res. (In press).

36. DEMAR Jr. JC, MA K, BELL JM, RAPOPORT SI. Half-lives of docosahexaenoic acid in rat brain phospholipids are prolonged by 15 weeks of nutritional deprivation of $\mathrm{n}-3$ polyunsaturated fatty acids. / Neurochem 2004; 91: 1125-37.

37. RAPOPORT SI, CHANG MC, SPECTORAA Delivery and turnover of plasma-derived essential PUFAs in mammalian brain. / Lipid Res 2001. 42: 678-85

38. PURDON D, ARAIT, RAPOPORT S. No evidence for direct incorporation of esterified palmitic acid from plasma into brain lipids of awake adult rat. / Lipid Res 1997; 38: 526-30.

39. CHANG MC, ARAIT, FREED LM, et al. Brain incorporation of $\left[1-{ }^{11} \mathrm{C}\right]$-arachidonate in normocapnic and hypercapnic monkeys, measured with positron emission tomography. Brain Res 1997; 755: 74-83.
40. LANDS WEM, CRAWFORD CG. Enzymes of membrane phospholipid metabolism. In: Martonosi A, ed. The Enzymes of Biological Membranes, Vol. 2. New York: Plenum, 1976: 3-85.

41. SHETTY HU, SMITH QR, WASHIZAKI K, RAPOPORT SI, PURDON AD. Identification of two molecular species of rat brain phosphatidylcholine that rapidly incorporate and turn over arachidonic acid in vivo. / Neurochem 1996; 67: 1702-10.

42. BASSELIN M, CHANG L, BELL JM, RAPOPORT SI. Chronic Lithium Chloride Administration Attenuates Brain NMDA Receptor-Initiated Signaling via Arachidonic Acid in Unanesthetized Rats. Neuropsychopharmacology 2006; 31: 1659-74.

43. PURDON AD, RAPOPORT SI. Energy requirements for two aspects of phospholipid metabolism in mammalian brain. Biochem / 1998; 335: 313-8.

44. IGARASHI M, MA K, CHANG L, BELL JM, RAPOPORT SI, DEMAR Jr. JC. Low liver conversion rate of alpha-linolenic to docosahexaenoic acid in awake rats on a high-docosahexaenoatecontaining diet. / Lipid Res 2006; 47: 1812-22.

45. DEMAR Jr. JC, MAK, BELL JM, IGARASHI M, GREENSTEIN D, RAPOPORT SI. One generation of $n-3$ polyunsaturated fatty acid deprivation increases depression and aggression test scores in rats. J Lipid Res 2006; 47: 172-80.

46. CONTRERAS MA, CHANG MC, KIRKBY D, BELL JM, RAPOPORT SI. Reduced palmitate turnover in brain phospholipids of pentobarbitalanesthetized rats. Neurochem Res 1999; 24: 833-41.

47. CONTRERAS MA, CHANG MC, ROSENBERGER TA, et al. Chronic nutritional deprivation of $n-3$ alpha-linolenic acid does not affect n-6 arachidonic acid recycling within brain phospholipids of awake rats. I Neurochem 2001; 79 : 1090-9.

48. GIOVACCHINI G, CHANG MC, CHANNING MA, et al. Brain incorporation of [11C]arachidonic acid in young healthy humans measured with positron emission tomography. I Cereb Blood Flow Metab 2002; 22: 1453-62.

49. GIOVACCHINI G, LERNER A, TOCZEK MT, et al. Brain incorporation of $11 \mathrm{C}$-arachidonic acid, blood volume, and blood flow in healthy aging: a study with partial-volume correction. I Nucl Med 2004; 45: 1471-9.

50. ESPOSITO G, GIOVACCHINI G, DER M, et al. Imaging signal transduction via arachidonic acid in the human brain during visual stimulation, by means of positron emission tomography. Neuroimage 2007; 34: 1342-51.

51. CHANNING MA, SIMPSON N. Radiosynthesis of 1-[11C]polyhomoallylic fatty acids. J Labeled Compounds Radiopharmacol 1993; 33: 541-6. 
52. FOOD AND NUTRITIONBOARD. In: Dietary Reference Intakes for Energy, Carbohydrate, Fiber, Fat, Fatty Acids, Cholesterol, Protein and Amino Acids (Macronutrients). Washington, DC: National Academies Press, 2005: 1331

53. ROSELL MS, LLOYD-WRIGHT Z, APPLEBY PN, SANDERS TA, ALLEN NE, KEY TJ. Long-chain $\mathrm{n}-3$ polyunsaturated fatty acids in plasma in British meat-eating, vegetarian, and vegan men. Am / Clin Nutr 2005; 82: 327-34.

54. WIGGINS D, GIBBONS GF. The lipolysis/ esterification cycle of hepatic triacylglycerol. Its role in the secretion of very-low-density lipoprotein and its response to hormones and sulphonylureas. Biochem / 1992; 284(Pt 2): 45762.

55. SAUERWALD TU, HACHEY DL, JENSEN CL, CHEN H, ANDERSON RE, HEIRD WC. Intermediates in endogenous synthesis of $\mathrm{C} 22: 6$ omega 3 and C20:4 omega 6 by term and preterm infants. Pediatr Res 1997; 41: 183-7.

56. RAO JS, ERTLEY RN, DEMAR Jr. JC, RAPOPORT SI, BAZINET RP, LEE HJ. Dietary n-3 PUFA deprivation alters expression of enzymes of the arachidonic and docosahexaenoic acid cascades in rat frontal cortex. Mol Psychiatry 2007; 12: 151-7.

57. MURAKAMI M, KAMBE T, SHIMBARA S, KUDO I. Functional coupling between various phospholipase A2s and cyclooxygenases in immediate and delayed prostanoid biosynthetic pathways. / Biol Chem 1999; 274: 310315.
58. BOSETTI F, WEERASINGHE GR. The expression of brain cyclooxygenase- 2 is down-regulated in the cytosolic phospholipase A2 knockout mouse. / Neurochem 2003; 87: 1471-7.

59. BAZAN NG, AVELDANO DE CALDIRONI MI, RODRIGUEZ DE TURCO EB. Rapid release of free arachidonic acid in the central nervous system due to stimulation. Prog Lipid Res 1981; 20: 523-9.

60. $\mathrm{CHOI} \mathrm{SH,} \mathrm{LANGENBACH} \mathrm{R,} \mathrm{BOSETTI} \mathrm{F.}$ Cyclooxygenase-1 and -2 enzymes differentially regulate the brain upstream NF-kappaB pathway and downstream enzymes involved in prostaglandin biosynthesis. J Neurochem 2006; 98: 801-11

61. ROSENBERGER TA, VILLACRESES NE, HOVDA JT, et al. Rat brain arachidonic acid metabolism is increased by a 6-day intracerebral ventricular infusion of bacterial lipopolysaccharide. J Neurochem 2004; 88: 1168-78.

62. BASSELIN M, VILLACRESES NE, LEE HJ, BELL JM, RAPOPORT SI. Chronic lithium administration attenuates up-regulated brain arachidonic acid metabolism in a rat model of neuroinflammation. J Neurochem 2007.

63. RABIN O, CHANG MC, GRANGE E, et al. Selective acceleration of arachidonic acid reincorporation into brain membrane phospholipid following transient ischemia in awake gerbil. I Neurochem 1998; 70: 325-34.
64. KRYSTAL JH, SANACORA G, BLUMBERG $\mathrm{H}$, et al. Glutamate and GABA systems as targets for novel antidepressant and mood-stabilizing treatments. Mol Psychiatry 2002; 7(Suppl 1): S71-S80.

65. MCGEER EG, MCGEER PL. Inflammatory processes in Alzheimer's disease. Prog Neuropsychopharmacol Biol Psychiatry 2003; 27: 741-9.

66. CHAO MV, RAJAGOPAL R, LEE FS. Neurotrophin signalling in health and disease. Clin Sci (Lond) 2006; 110: 167-73.

67. RAO JS, ERTLEY RN, LEE HJ, et al. n-3 polyunsaturated fatty acid deprivation in rats decreases frontal cortex BDNF via a p38 MAPKdependent mechanism. Mol Psychiatry 2007; 12: $36-46$.

68. CONTRERAS MA, GREINER RS, CHANG MC, MYERS CS, SALEM Jr. N, RAPOPORT SI. Nutritional deprivation of alpha-linolenic acid decreases but does not abolish turnover and availability of unacylated docosahexaenoic acid and docosahexaenoyl-CoA in rat brain. I Neurochem 2000; 75: 2392-400.

69. CHANG MC, BELL JM, PURDON AD, CHIKHALEEG, GRANGEE. Dynamics of docosahexaenoic acid metabolism in the central nervous system: lack of effect of chronic lithium treatment. Neurochem Res 1999; 24: 399-406. 